\section{Questión}

Periodismo / Comunicación ISSN 1669-6581
- Av. $44 \mathrm{~N}^{\circ} 676,1^{\circ}$ piso

CP 1900 - La Plata - Argentina

(i) www.perio.unlp.edu.ar/question

El derecho a la educación en cárceles en contexto de pandemia. Experiencias de la extensión áulica UNLP

Zapata Natalia, Pascolini Julia, García Malena, Irimia Romina

DOI: https://doi.org/10.24215/16696581e317

\title{
El derecho a la educación en cárceles en contexto de pandemia. Experiencia de la extensión áulica UNLP
}

The right to education in prisons in the context of the pandemic. UNLP Extension Experience

Zapata, Natalia nataliazapata01@gmail.com

Pascolini, Julia pascoliniju@gmail.com

García, Malena malena_garcia@live.com

Irimia, Romina irimia.ro@gmail.com

\section{Palabras Clave}

Educación - Cárcel - Pandemia - Extensión

Key Words

Education - Prison - Pandemic - Extension

Introducción

Este trabajo toma su forma ante la oportuna invitación realizada por el equipo de la revista Questión/Cuestión para hacemos preguntas, y cuestionarnos las respuestas, ante los atravesamientos que genera el Covid-19 en nuestras prácticas cotidianas.

Y aquí interpeladas por la invitación, y por la intervención docente en contextos de encierro, proponemos esta producción colectiva en donde reflexionamos sobre la compleja amenaza que genera la idea de la pandemia en las cárceles; el encierro punitivo y el aislamiento obligatorio; 
los derechos educativos y de la educación superior en cárceles y también sobre el rol de los medios de comunicación.

El 11 de marzo la Organización Mundial de la Salud (OMS) declaró que el brote de coronavirus-Covid19 dejaba de ser una epidemia y pasaba a ser una pandemia. El mundo primero se preguntó ¿Y ahora qué hacemos? Al día siguiente, en nuestro país se decretó la emergencia pública en materia sanitaria por el plazo de un año en virtud de la pandemia declarada.

En ese contexto, y en poco tiempo el mundo cambió. Todos los países comenzaron a tomar medidas sanitarias de urgencia para paliar el virus. La principal y más extendida es la denominada cuarentena, que debe cumplirse, mayormente, en el domicilio de cada une 0 , al menos, en el ámbito doméstico donde la cuarentena le sorprendiera.

Como dicen los editores comunitarios de Wikipedia en el artículo referido a "cuarentena" (que ha tenido un total de 1.488.370 de visitas en los últimos sesenta días)i, en el marco medicinal, es un término que se utiliza "para describir el aislamiento de personas o animales durante un período de tiempo no específico como método para evitar o limitar el riesgo de que se extienda una enfermedad o una plaga".

Haciendo un poco de historia, sabemos que entre 1346 y 1347 estalló la mayor epidemia de peste de la historia de Europa: la denominada peste negra o bubónica. Era una enfermedad conocida por sus antecedentes, sin embargo, se ignoraba por completo tanto sus causas como su tratamiento. Esto, junto con la gran velocidad de propagación, la convirtió en una de las mayores pandemias de la historia. Las personas comenzaron a aislarse para evitar enfermarse y morir. De algún modo implementaron la cuarentena como medida sanitaria.

Desde aquellos tiempos, la cuarentena o el aislamiento de personas o poblaciones, aparece como medida sanitaria pertinente para combatir distintas enfermedades. La última cuarentena "famosa" ha sido la implementada en China por el SARS (síndrome respiratorio agudo grave) durante el 2009. Pero en la historia reciente de Argentina esta medida es novedosa.

De repente, estamos confinados a nuestros espacios domésticos desde el 20 de marzo por indicación del gobierno y la autoridad sanitaria nacional, a partir del Decreto de Necesidad y Urgencia DNU 297/2020. Desde allí ingresamos al Aislamiento Social Preventivo y Obligatorio (ASPO). Al momento de la escritura de este artículo, hubo dos decretos de extensiones de este 
decreto tendientes a prolongar el tiempo de aislamiento social y a "flexibilizar" algunas actividades.

Esta medida transformó la cotidianidad del país porque se cerraron las fronteras, se suspendieron las clases educativas presenciales, los negocios y empresas debieron bajar sus persianas, se cancelaron espectáculos artísticos y deportivos, ya no hubo más fiestas, ni bares y restaurantes; ni cines, teatros, centros culturales, bibliotecas, museos, gimnasios, clubes y cualquier espacio público o privado que implique la concurrencia de personas.

Ya no hubo más reuniones familiares, ni besos ni abrazos. Para la mayoría, sólo salidas esenciales al supermercado y farmacia. Para quienes trabajan en salud, seguridad, transporte público, alimentación y otros rubros considerados servicios esenciales, salir a la calle implica un desafío inusual. También hubo mucha gente que violó estas medidas de ASPO y se iniciaron en todo el país miles de detenciones y notificaciones de inicio de causas penales.

En lo vinculado al espacio educativo en particular, la transformación fue rápida y bastante particular. A partir del DNU presidencial, el Ministerio de Educación de la Nación (MEN) emitió una resolución específica para el ámbito de incumbencia y comenzó a desarrollar en tiempo récord materiales pedagógicos para la continuidad educativa en un contexto inédito donde miles de alumnes y docentes ya no se pueden encontrar como siempre.

En un trabajo articulado con la Secretaría de Medios y Comunicación Pública y otras áreas gubernamentales, el MEN implementó la plataforma "Seguimos educando", que se presenta como un sistema con herramientas pedagógicas (programas de radio y TV, cuadernillos para estudiantes y plataforma web) que trabaja en conjunto con canales de la TDA, Encuentro, DeporTV y TV Pública. En esta iniciativa implementó cuadernillos de contenidos para niveles iniciales, primaria y secundaria que los equipos directivos y docentes se encargan de hacer llegar a les estudiantes.

En la Universidad, por su parte, las distintas unidades académicas se vieron ante el desafío de repensar el espacio áulico físico ante la prohibición de concentrar personas. En ese marco, muchas instituciones de educación superior plantearon la posibilidad de brindar clases a distancia, readecuar sus calendarios académicos e implementar diversas estrategias. Otras instituciones, como la Universidad de Buenos Aires, definieron retomar las actividades académicas a partir de junio (Res. 423/2020), aunque desde los primeros días de abril desde la 
Dirección del CBC se dispuso un plan de acompañamiento académico virtual para estudiantes, desde el mes de mayo, previo al inicio de clases presenciales.

Particularmente, la Universidad Nacional de La Plata (UNLP) emitió la resolución 667/2020 donde se estableció no desarrollar clases presenciales, adoptar medidas extraordinarias para cumplir con el ciclo lectivo y generar espacios de evaluación desdoblados y a distancia, entre otras medidas y acciones como la estrategia de capacitación a docentes y la disposición de herramientas específicas (gestión de licencias para implementar dispositivos para videoconferencias, entre otras acciones).

En este contexto, la Facultad de Periodismo y Comunicación Social (FPyCS) de la UNLP, donde las autoras de este artículo participamos como estudiantes, docentes, adscriptas a la docencia, investigadoras y extensionistas, en sintonía con la resolución de Presidencia de la universidad, suspendió las clases presenciales en todas las sedes y comenzó a implementar acciones para reprogramar el calendario académico y generar estrategias de educación a distancia, con apoyo de herramientas pedagógicas.

En ese marco, las cátedras comenzaron a adecuar sus propuestas a los recursos disponibles, a sumar nuevos y a desarrollar estrategias pedagógicas situadas para llevar las clases a las distintas sedes. En nuestro caso, la cátedra en la que nos desempeñamos se dicta en la sede Bosque y en la "Extensión Áulica Unidad 9", una de las sedes territoriales de la Facultadii.

Ante el nuevo desafío nos preguntamos ¿Qué acción pedagógica es posible en contexto de pandemia? ¿Qué acción pedagógica es posible en un contexto de doble encierro? E intentamos ensayar algunas reflexiones que permitieran reponer ese lugar edificante de otros modos de ver el mundo que tiene la educación tras los muros.

Nos preguntamos y nos cuestionamos sobre los temas que trabajamos en nuestra materia y cómo nos interpela, en esta intervención particular, el hecho de pensar las modernidades, los medios y el poder cuando educamos en un contexto de encierro punitivo atravesado por la pandemia, nos planteamos allí qué limitaciones y contradicciones se nos presentan.

Ello nos llevó a ser operativas, a desarrollar una estrategia pedagógica posible, viable; a plantear recursos y herramientas; a hacernos nuevas preguntas sobre las continuidades de esta iniciativa en desarrollo. También a preguntarnos sobre el relato mediático que se construye sobre la situación carcelaria en medio de la emergencia. 
En consecuencia, el presente artículo plantea un recorrido sobre el desarrollo de la propuesta académica de la materia Modernidades, Medios y Poder Cat II de la FPyCS-UNLP para la Extensión Áulica Unidad 9, donde el atravesamiento de educar en contexto de encierro y emergencia sanitaria nos encuentra trabajando por el acceso al derecho a la educación pública y aún con más preguntas que certezas sobre las estrategias y sus posibilidades.

Pandemia en las cárceles. El encierro punitivo y el aislamiento obligatorio

Primeras medidas para prevenir una tragedia

En las cárceles la amenaza del coronavirus ya ha cobrado siete vidas al momento en que redactamos este artículoiii; se han generado reclamos, mediante distintas estrategias, por parte de personas detenidas a lo largo de todo el país, con acompañamiento fundamental de familiares y organizaciones que promueven derechos en ámbito de encierro punitivo. También universidades, referentes políticos, de la justicia y hasta el Papa Francisco se refirieron a la situación carcelaria en contexto de la pandemia.

Para dimensionar los efectos del COVID-19 en las cárceles, es necesario retroceder unos días antes de mediados de marzo, período en el cual se confirmaron los primeros casos positivos del virus en el país. Volver unos días atrás para describir cómo es una cárcel cuando una pandemia no atraviesa en todos los aspectos la vida social.

En Argentina hay 94.883 personas privadas de la libertad, incluyendo a quienes están detenidos/as en alcaldías (SNEEP, 2018). El 44,75\% de estas personas se encuentran detenidas en la Provincia de Buenos Aires. Hay cárceles con regímenes de máxima, media y mínima seguridad; de varones y jóvenes adultos, de mujeres; de madres con sus hijes menores de 4 años; pabellones que alojan población trans, pabellones evangélicos, de (buena) "conducta" y universitarios, entre otros.

Más allá de los elementos particulares que hacen distinto cada contexto de encierro, las cárceles comparten la problemática de la sobrepoblación, que es del 100\% según la Comisión Provincial por la Memoria (CPM). De acuerdo con los datos de su informe (CPM, 2019), hay 46.000 presos/as y 21.000 plazas en el sistema de la Provincia de Buenos Aires y 4.200 detenidos/as en comisarías, con apenas 1020 plazas disponibles. 
Este estado de superpoblación, que el Tribunal de Casación Penal de la provincia de Buenos Aires definió en diciembre de 2019 como de "crisis humanitaria", se manifiesta en muchos aspectos de la vida cotidiana de las personas privadas de la libertad. Se manifiesta en la alimentación, en la escasez de elementos de higiene, en el personal médico insuficiente en relación con el volumen de población, en la imposibilidad de tener intimidad, en la falta de cupos para realizar actividades laborales, educativas o recreativas.

A su vez, el contexto de hacinamiento implica que en la cárcel muchas veces las personas detenidas mueren por enfermedades curables (como la tuberculosis). De esta forma, la población carcelaria constituye en sí misma una población de riesgo, porque hay muchísimos/as detenidos/as con VIH-Sida; asma, tuberculosis y hepatitis, lo cual representa una situación de vulnerabilidad específicamente grave para el contagio de enfermedades virales. Y esta situación se agrava ante la amenaza del virus.

El artículo 18 de la Constitución Nacional es muy claro cuando señala que las cárceles son para seguridad y no para castigo. Las personas que están entre rejas deben tener la seguridad de que van a pasar allí un tiempo sin riesgo de muerte. $Y$ esa garantía de seguridad la tiene que dar el Estado, a través de los órganos ejecutivos, para garantizar las condiciones dignas de detención y de la Justicia que supervisa la ejecución de las penas.

Con la llegada del virus COVID-19 al país, el gobierno nacional comenzó a implementar una serie de medidas para evitar la propagación exponencial del virus y "amesetar" la curva de contagio, como el aislamiento preventivo y obligatorio y el cierre de fronteras. La pandemia puso de relieve condiciones de desigualdad que ya se venían manifestando desde tiempo atrás. Así se discutió que el \#YoMeQuedoEnCasa no significa lo mismo para quienes habitan viviendas precarias o necesitan salir a trabajar en la vía pública diariamente para generar un ingreso, como los/as vendedores/as ambulantes. También se lanzaron medidas para contener la situación de estos sectores, a través de bonos, refuerzo de presupuesto de comedores y merenderos y suspensión de cortes por falta de pago de los servicios públicos, entre otras.

En el caso de las cárceles, durante el primer período -antes del aislamiento social obligatorioel personal de salud comenzó a hacer controles en las visitas, chequeos de la temperatura corporal y declaraciones juradas. Unas semanas después, el Ministerio de Justicia y Derechos Humanos bonaerense habilitó un permiso de circulación para familiares de personas detenidas, considerando el rol que cumplen acercando elementos de higiene y alimentos a las cárceles, 
además de la contención y el afecto. No obstante, en muchas Unidades Penitenciarias fueron las mismas personas detenidas las que decidieron suspender las visitas. Las primeras fueron las mujeres detenidas en la Unidad №50 de Batán; y luego terminó por extenderse en todas las cárceles.

A fines de marzo, el Subcomité de Prevención de la Tortura emitió una serie de recomendaciones a los Estados parte y Mecanismos Nacionales de Prevención, tendientes a reducir las poblaciones penitenciarias. $\mathrm{Y}$ en los primeros días de abril, un grupo de defensores generales de la provincia de Buenos Aires presentaron un habeas corpus colectivo y correctivo ante instancias de casación penal de la Provincia, con el objeto de denunciar la "ilegalidad e inconstitucionalidad" de las condiciones en las que se cumplen los encierros, y que sean consideradas las situaciones de aquellas personas detenidas en cárceles y comisarías, que se encuadran en la población de riesgo.

En consecuencia, el Tribunal de Casación Penal (TCP) otorgó prisiones domiciliarias para la población de riesgo, identificadas en los listados aportados por el Ministerio de Justicia y Derechos Humanos y el Ministerio de Seguridad, ambos de la Provincia de Buenos Aires: mayores de 65 años; personas con problemas de salud respiratorios, renales, cardiovasculares, entre otros; y mujeres embarazadas y/o que conviven con sus hijes que no hubieran cometido delitos violentos.

Es muy claro el fallo cuando enfatiza que cada juzgado o tribunal que atiende la causa, "debe evaluar la necesidad u oportunidad de disponer una medida de arresto domiciliario (en cuyo caso, y cuando corresponda, deberá resguardarse la integridad psicofísica de la víctima), o bien, asegurando el aislamiento sanitario dentro de la Unidad Penitenciaria donde cada uno se encuentra alojado".

Además, por medio de la resolución 52-20 de la Suprema Corte de Justicia de la Provincia de Buenos Aires (SCJBA), respondió al planteo realizado por el Ministerio de Justicia y DDHH, CELS y CPM y en el documento subrayó que es atribución de los jueces y juezas resolver medidas alternativas y prisión domiciliaria para los grupos de personas detenidas mencionados anteriormente.iv

Estas resoluciones judiciales generaron un debate con ribetes insólitos en los espacios mediáticos y políticos. Incluso diputades nacionales hablaron de un "plan del Gobierno para liberar detenidos con la excusa del coronavirus". Tal es así, que gobernadores, ministros, 
ministras y hasta el propio presidente de la Nación salieron a desmentir estas versiones. También desde el Gobierno nacional se alertó que no se dispondrán indultos, ni amnistías, ni conmutación de penas y se resaltó que el Poder Judicial es quien toma la decisión de detener a una persona, enviarla a un centro de detención y/o excarcelarla. Volveremos más adelante con la construcción discursiva sobre este tema.

Teléfonos celulares en las cárceles

Volviendo al caso de las cárceles provinciales y las medidas iniciales, tenemos que, ante la falta de las visitas de familiares, el TCP dictó una medida cautelar en favor de las detenidas y detenidos en la provincia de Buenos Aires durante la vigencia de la cuarentena. La misma fue instrumentada por el SPB, que se encuentra bajo la órbita del Ministerio de Justicia y Derechos Humanos de la Provincia, mediante un protocolo normativov, se trata de la habilitación oficial para la tenencia de teléfonos celulares y otros dispositivos tecnológicos móviles (como computadoras y tablets) en los penales bonaerenses, a fin de mantener los vínculos con sus familiares.

Al mismo tiempo, el referido protocolo plantea entre los objetivos esenciales, además de facilitarle a la población privada de la libertad el contacto con sus familiares y afectos; uno relacionado con su desarrollo educativo y cultural y especifica otro vinculado con el acceso a información relativa a su situación procesal.

A partir de esta habilitación, el SPB elabora un registro exhaustivo de los celulares existentes: el viernes 3 de abril, en la Unidad Penitenciaria $N^{\circ} 6$ de Dolores, se tomaba una foto histórica, donde algunos detenidos registraban ante las autoridades penitenciarias los celulares que hasta ese momento tenían clandestinamente. Los cuestionamientos a esta medida, fundamentados en sentidos que asocian al delito como una práctica totalmente desvinculada de la supervivencia económica o el paradigma de consumo, sostenían que la tenencia de celulares iba a tener como fin la planificación y ejecución de delitos como los secuestros virtuales o las extorsiones.

No obstante, para las personas privadas de la libertad, el acceso a teléfonos celulares supone la posibilidad de sostener sus redes familiares y comunitarias. Además, su acceso permite, también, contactarse con operadores judiciales (fundamentalmente, abogados/as defensores/as), con organismos de derechos humanos y también informarse acerca de la 
situación social. A su vez, los teléfonos celulares pueden aportar a la continuidad educativa, posibilidad sobre la que volveremos más adelante. De esta forma, el derecho a la comunicación abre la puerta al ejercicio de otros derechos.

(Re)acciones desde el ámbito académico

A partir del trabajo cotidiano en el territorio carcelario desde la investigación, la docencia y la extensión, las Universidades Públicas comenzaron a llevar adelante algunas acciones para visibilizar e intervenir sobre esta problemática, que se extiende en las prisiones de todo el país, con el fin de que se atienda la emergencia en este contexto y de proteger y efectivizar el acceso al derecho a la salud y garantizar las condiciones de higiene de las personas privadas de la libertad.

El 20 de marzo El Grupo de Trabajo CLACSO "Barrios, familias y prisiones en circuito" emitió un informe manifestando su profunda preocupación por la situación de las cárceles latinoamericanas en general y argentinas en particular. Allí propone, además, una serie de recomendaciones, entre las que se incluye: la implementación urgente de políticas específicas que protejan a la población detenida y los trabajadores penitenciarios; concesión de arrestos domiciliarios; participación de la población afectada en la formulación de políticas de gobierno y creación de una comisión interdisciplinaria independiente para la investigación de las muertes. Cinco días después, el Programa Educación Universitaria en Prisiones y el Programa Delito y Sociedad de la Universidad Nacional del Litoral planteó públicamente un conjunto de señalamientos y propuestas orientadas a contribuir a la reducción de los daños y de la vulneración de derechos de la población privada de su libertad. El informe fue publicado en una versión de nota periodística en el diario Página/12 titulado "Propuestas ante la crisis carcelaria". En ese marco, también la Mesa Interuniversitaria Nacional de Educación en Contextos de Encierrovi, integrada por programas y proyectos de Universidades Nacionales con trabajo en instituciones penales de todo el país, emitió un comunicado manifestando la preocupación por la situación de las cárceles en el marco de la pandemia. En dicho comunicado, que firmó la UNLP, se remarca que las condiciones de hacinamiento y superpoblación implican profundas dificultades para prevenir el contagio del COVID-19, como la limpieza y ventilación de espacios. En relación con este diagnóstico, se propuso reducir la sobrepoblación a partir de medidas como limitar el uso de la prisión preventiva, y permitir libertades anticipadas en casos de delitos 
no violentos; así como también garantizar las condiciones de prevención del COVID-19 a partir de la provisión de insumos sanitarios de prevención, higiene y limpieza.

Estas lecturas y pronunciamientos sobre la problemática están en sintonía con los organismos de salud (OMS) y otros de derechos humanos del mundo, que fueron replicadas por organizaciones locales como la CPM y el CELS, quienes presentaron al Ejecutivo recomendaciones para reducir la sobrepoblación carcelaria como estrategia fundamental de prevención. Y también en sintonía con la resolución del TCP de la provincia de Buenos Aires al que referimos y con las recomendaciones de la Cámara de Casación a nivel federal.

En definitiva, la sobrepoblación no es un fenómeno coyuntural, sino que constituye una problemática estructural desde hace décadas, producto de las sucesivas declaraciones de emergencia en seguridad, del uso excesivo de la prisión preventiva, de la demanda de mayor punitivismo por parte de la sociedad y la creciente disposición de policía en el espacio público (Rodríguez Alzueta, 2020).

Desde la segunda semana de abril 2020 observamos que se ampliaron las acciones llevadas adelante por los espacios académicos, por medio de estrategias de acercamiento; la visibilización y la realización de operatorias para llevar elementos de higiene a los lugares de encierro:

- UNLP: desde proyectos de extensión y agrupaciones estudiantiles con trabajo en cárceles, se emprendieron campañas de donación de elementos de higiene, alimentos y celulares; desde los programas académicos de las distintas unidades académicas se impulsaron acciones de acompañamiento estudiantil, mediante recursos virtuales y actividades académicas como las cursadas a distancia que impulsa la FPyCS. Asimismo, distintos espacios institucionales manifestaron adhesiones y rubricaron los pronunciamientos colectivos de las Universidades Nacionales.

- La UNICEN: se propuso llevar a cabo una campaña de donaciones ante la emergencia. Los insumos se dejan en un supermercado (Cooperativa Obrera de Olavarría) y la coordinadora del Programa retira y deriva a las unidades carcelarias de la región donde la Universidad tiene estudiantes.

- UBA XXII: además de efectuar pronunciamientos, en un trabajo conjunto con el INADI el programa hizo entrega de donaciones en cárceles federales. Se activó una campaña de recaudación de fondos para la compra de alimentos, pañales, abrigo e insumos de 
higiene y cuidado para los vínculos territoriales construidos en el Centro de Extensión CIDAC y el Programa de Extensión en Cárceles (Devoto y Ezeiza).

- UNCUYO: comunicó, por medio de sus website, las acciones académicas que incluye entrega de materiales de estudio impreso y abordaje psicopedagógico, además de asesoramiento a estudiantes para las cursadas virtuales.

- UNC: replicó en su website el documento del Comité Nacional de Prevención de la Tortura con las recomendaciones para reducir la población en cárceles.

Por su parte, la coordinadora del Programa de Extensión Universitario en Contextos de Encierro de la Universidad Nacional de Catamarca alertó sobre la situación sanitaria de las mujeres detenidas. El artículo que publicó el diario Página/12 titulado "El doble aislamiento de las detenidas en plena pandemia del coronavirus", problematiza sobre la vulneración de los derechos, como, por ejemplo, el de obtener la prisión domiciliaria si se tienen hijes pequeños. Se remarca que "la crisis sanitaria agrava una situación estructural que encuentra en cada penal a más procesadas que condenadas, y con mayoría de presas por narcomenudeo".

Cabe destacar, también desde el ámbito académico el informe elaborado por la Comisión de Ciencias Sociales de la Unidad COVID-19 del CONICET que relevó los alcances de los primeros días de cuarentena. Este trabajo sirvió como asesoramiento para el Poder Ejecutivo y, en este caso nos invita a considerar el impacto social del aislamiento social obligatorio y preventivo en distintos espacios y en la cárcel en particular.

La estrategia desplegada por les investigadores se basó en contactar a informantes clave de las universidades -referentes académicos de Sociología, Antropología, Trabajo Social, Ciencias Políticas, Educación, entre otras disciplinas- que tuvieran a su vez vínculos con referentes locales -gente que viva en el territorio específico que se buscaba relevar. respecto de la población en situación carcelaria de la provincia de Buenos Aires:

"los informantes señalan una serie de problemas específicos de esta población: falta de comunicación con las familias; falta de cumplimiento de la agencia penitenciaria respecto de normas de seguridad e higiene; falta de medidas de prevención respecto del contagio en condiciones de sobrepoblación carcelaria; suspensión de actividades deportivas, recreativas y educativas, entre muchos otros problemas agravados" (CONICET, 2020:23) A partir de algunos casos de agentes penitenciarios y de, al menos una persona privada de la libertad, confirmados de COVID-19 en la Provincia y el ámbito federal (y de múltiples agentes 
penitenciarios como casos "sospechosos"), los motines y otras manifestaciones que se empezaron a desatar en los establecimientos penitenciarios. En ese marco, la Mesa Interuniversitaria y un conjunto de organizaciones sociales, sindicales, culturales y políticas emitió una Declaración conjunta sobre la "extrema preocupación por la situación de tensión y violencia" vivenciada en las cárceles.

En el cierre de este artículo, la situación nos encuentra con el tema instalado en la agenda mediática como nunca antes: se está hablando de "liberaciones en masa"; se está sugiriendo que hay un "plan del Gobierno para liberar presos", se firman notas de opinión con títulos sugestivos: "Violadores, femicidas, secuestradores y narcos: los presos con domiciliaria por el coronavirus"; se está convocando a cacerolazos masivos bajo el lema "no liberen a los presos", entre otras acciones discursivas carentes de rigurosidad informativa.

La garantía de los derechos educativos en contexto de encierro punitivo En una entrevista al diario Página/12, del 19 de abril pasado, el juez de la Corte Interamericana de Derechos Humanos Eugenio Zaffaroni alertó que "una situación de emergencia es siempre ocasión para toda clase de racionalizaciones de múltiples violaciones de derechos humanos". En tal sentido, el titular de cuatro decenas de honoris causa, señaló la necesidad de equilibrar lo que hace a los derechos elementales, "teniendo cuidado de que no se aproveche ese difícil equilibrio para filtrar pretextos o legitimar intereses sectoriales y mezquinos".

La sociedad contemporánea reconoce que todo ser humano, por el hecho de serlo, tiene derechos frente al Estado, quien tiene el deber de respetar y garantizar o bien está llamado a organizar su acción a fin de satisfacer su plena realización (Niken, 1994). La amenaza de la pandemia en las cárceles instaló un debate donde se plantea una fuerte tensión entre salud/seguridad. En este marco, el derecho a la educación no puede ser visto por encima ni por debajo de los demás derechos.

Como señalamos en el apartado anterior, en la coyuntura de la pandemia, desde distintos espacios organizacionales se comenzaron a nuclear y a activar acciones para demandar al Estado respuestas urgentes para la atención sanitaria y alimentaria. También la medida cautelar del TCP para habilitar el uso de celulares y otros dispositivos técnicos, se presenta como una respuesta inédita para garantizar el derecho a la comunicación en las cárceles 
bonaerenses, medida que fue replicada en otras provincias, pero en otras se subrayó su prohibición o directamente aun no se pronunció (como en el ámbito Federal).

Asimismo, el dispositivo tecnológico en el ámbito de la cárcel abre la posibilidad, no sólo de comunicarse con la familia, denunciar situaciones de abuso y violencia institucional, sino que, además, se presenta como un recurso de significativo valor de uso, en el marco de la política nacional de continuidad pedagógica a la que hicimos referencia. No sin tensiones y contradicciones, por supuesto.

Partimos de comprender a la educación como un derecho humano fundamental, que como dice el ex relator de la UNESCO, Vernor Muñoz (2004), hace posible el ejercicio de otros derechos humanos fundamentales y, en consecuencia, de la ciudadanía:

Difícilmente se podrá acceder a un empleo digno, o ejercer la libertad de expresión o de participación, si no se tiene educación. Esto supone que no puede ser considerada como un mero servicio o una mercancía negociable, sino como un derecho que el Estado tiene la obligación de respetar, asegurar, proteger y promover. Los servicios pueden ser diferidos, pospuestos y hasta negados, mientras que un derecho es exigible y justiciable por las consecuencias que se derivan de su violación o irrespeto (Muñoz, 2004).

$Y$ en el contexto de encierro este derecho se encuentra normativizado con marcos legales específicos.

Marcos normativos sobre educación en la privación de libertad

Para la modalidad de la educación en prisiones existe un marco de carácter jurídico-político, tanto en la jurisdicción provincial como nacional e internacional que contempla las particularidades del contexto para garantizar el derecho educativo de quienes están en situación de privación de la libertad, entre los que se reconoce:

- la Constitución Nacional de la República Argentina que, a su vez, contempla los ordenamientos y tratados internacionales; 
- la Ley de Educación Nacional (LEN N²6.206/06), específicamente el Capítulo artículo XII que plantea la modalidad Educación en ámbitos de privación de la libertad;

- la denominada "Ley de Estímulo Educativo" (№ 26.695/11);

- las leyes de Ejecución Penal (nacional y provinciales);

- los convenios específicos entre Ministerios e instituciones educativas.

Particularmente en lo que respecta a educación superior, cabe considerar la Ley de Educación Superior (LES), promulgada 1995, normativa que significa mucho para la lucha del movimiento estudiantil y los distintos claustros universitarios que se movilizaron tomando las calles y los edificios universitarios para impedir que se avance con un intento de arancelamiento y eventual privatización de la educación en la universidad

De esta normativa podemos reconocer la incorporación de un artículo que ha resultado significativo para el acceso educativo en el nivel superior de personas privadas de libertad. Nos referimos al artículo séptimo que plantea lo siguiente:

"las personas mayores de 25 años que no aprobaron la educación secundaria también pueden ingresar a la educación superior si demuestran que tienen preparación, experiencia laboral, aptitudes y conocimientos suficientes para cursar los estudios a los que quieren ingresar".

Tensiones y contradicciones institucionales

Hay que tener presente que contar con un marco legal es condición necesaria pero no suficiente para garantizar el acceso y disfrute de los derechos. En tal sentido, en lo referente a la garantía de la educación en ámbitos de privación de la libertad, consideramos relevante tener presentes las tensiones y contradicciones que caracterizan a la educación en contexto de encierro, si pretendemos contribuir de manera genuina en los procesos de inclusión educativa de las personas privadas de libertad a través del acceso al sistema educativo:

- la interacción con sujetos insertos en múltiples atravesamientos institucionales (la unidad carcelaria; el órgano judicial que atiende su causa; la institución educativa.

- la ponderación de lo asegurativo por sobre lo educativo que prima en la institución de encierro donde se desarrollan las actividades educativas. 
- la concepción de la educación como "beneficio" y no como "derecho" por parte de muchos actores del ámbito penal, toda vez que se requiere garantizar las condiciones para que la persona que está en situación de cárcel pueda estudiar.

En medio de este entramado institucional, de las tensiones y contradicciones que se presentan, la persona privada de libertad ambulatoria que pretende estudiar (y sobre todo emprender el desarrollo de una carrera universitaria) desde la cárcel encuentra muchas limitaciones provenientes de la burocracia administrativa, propia de cada estamento del Estado y de cada cultura organizacional (Zapata y Nieto, 2012).

Criterios para monitorear el desarrollo del derecho

Dada la complejidad presentada, consideramos que la propuesta de las 4 Aes como indicadoras del desarrollo de la educación, se vuelve fundamental en términos de valorar durante el diseño y desarrollo de la acción educativa los criterios de realización del derecho. Siguiendo a Scarfo y Zapata (2013), estas cuatro aes se pueden resumir de la siguiente manera:

- accesibilidad: que el sistema sea no discriminatorio, que se presente accesible a todos y que se adopten medidas positivas no sólo en lo referido al acceso, sino también la permanencia y egreso del sistema educativo.

- asequibilidad: que la enseñanza sea gratuita, financiada por el Estado, y que exista una infraestructura adecuada y docentes formados, capaces de sostener la prestación de educación. Es decir, que la educación esté disponible.

- adaptabilidad: que la educación pueda transformarse a medida que cambian las necesidades de la sociedad, que pueda contribuir a superar las desigualdades - como la discriminación de género-, y que pueda adaptarse localmente para adecuarse a contextos específicos. Es decir, una educación dirigida a un sujeto singular (persona privada de la libertad) y a un contexto específico (la cárcel).

- aceptabilidad: que el contenido y los métodos de la enseñanza sean relevantes éticamente, no discriminatorios, culturalmente apropiados, de calidad y consecuentes con la Educación en Derechos Humanos.

Desarrollo de la educación superior en contexto de encierro 
Desde la introducción de un capítulo específico en la LEN, las universidades nacionales, a lo largo y ancho del país, han ido colocando en sus agendas de trabajo al territorio carcelario, desde la extensión, la investigación y la enseñanza. En algunos casos estableciendo acuerdos con las áreas del Ejecutivo para favorecer el acceso y permanencia en la Educación Superior de manera presencial y/o por medio de un sistema gratuito de educación a distancia, tal como lo prevé la normativa nacional en materia educativa.

En el ámbito de la UNLP en particular, desde entonces se vienen desarrollando iniciativas que posibilitan la presencia de la universidad en la cárcel y, consecuentemente, la presencia de la cárcel en la universidad. Sin embargo, en la actualidad sólo tres de sus 17 unidades académicas promueven acciones concretas para favorecer la inclusión en enseñanza de grado a personas que se encuentran en situación de cárcel.

- Facultad de Periodismo y Comunicación Social. A través del Programa de Educación Superior en Contextos de Encierro "EduCa", promueve una oferta de las carreras de grado Tecnicatura Superior Universitaria en Comunicación (Plan 2017) y Profesorado en Comunicación Social (Plan 1998); y de Posgrado (Maestría en Comunicación y Criminología Mediática; Maestría en Comunicación y DDHH).

- Facultad de Ciencias Jurídicas y Sociales. Por medio del Programa de Educación en Contextos de Encierro, oferta sus carreras de Grado: Abogacía; Procurador; Escribano $y$ en nivel de Posgrado otorga dos becas totales o parciales en toda la oferta académica (tiene estudiantes graduades en contexto de encierro que cursan la Especialización en Derecho Penal).

- Facultad de Humanidades y Ciencias de la Educación (FaHCE): a través del Programa de Acompañamiento a Estudiantes Privados/as de la Libertad promueve una serie de "acciones académicas tendientes a sostener y acompañar las trayectorias educativas universitarias de los/as estudiantes/as inscriptos/as en carreras de la Facultad de Humanidades y privados/as de la libertad en Unidades Penales cercanas a la Facultad": Lo hace por medio de clases de apoyo y grupos de estudio para rendir en modalidad libre materias de carreras de Grado: Profesorado en Historia y Profesorado en Sociología.

La UNLP cuenta con un Programa específico dedicado a la modalidad de privación de la libertad: el Programa de Acompañamiento Universitario en Cárceles (PAUC). Desde esta 
iniciativa se impulsan y coordinan las distintas actividades de la institución universitaria y sus Facultades en las cárceles de la región de La Plata. Además, se busca "implementar dispositivos propios para acompañar las trayectorias universitarias y de formación de los/as estudiantes privados/as de la libertad dentro de las cárceles y cuando recuperan la libertad, buscando promover su ingreso, permanencia y egreso en la Universidad Pública" (PAUC, 2020).

La extensión áulica Unidad 9 de la FPyCS

En el website de la Facultad se puede leer la historización de esta experiencia en un sentido cronológico:

"Este proceso comienza con el proyecto denominado "Comunicación en cárceles, una herramienta para el cambio", desarrollado durante el período 2006-2008, en donde se realizaron talleres de periodismo gráfico y radial en quince unidades carcelarias del Servicio Penitenciario Bonaerense."

"La Extensión Áulica Unidad Penitenciaria N No 9 se inició en el mes de octubre de 2009, como un engranaje más para garantizar el legítimo derecho a la educación de las personas privadas de libertad. (...). En la Extensión cursan personas privadas de su libertad alojadas tanto en la Unidad Penitenciaria № 9 como en otras unidades pertenecientes al Servicio Penitenciario Bonaerense".

"Desde 2007 -año en que comenzaron las inscripciones en la FPyCS- a la fecha, el número de inscriptas/os creció en un $80 \%$. Actualmente se registran más de 400 estudiantes inscriptas/os en la FPyCS, y aproximadamente 130 se encuentran activas/os, ya sea rindiendo materias libres, cursando en Extensión Unidad № 90 en Sede Néstor Kirchner".

"En el marco del programa EduCa, creado en 2012, sobre educación superior en contexto de encierro, se realizan desde hace años y sistemáticamente proyectos de voluntariado y extensión que han dejado como resultado producciones escritas, materiales gráficos y audiovisuales. En los últimos años han egresado las/os primeras/os compañeras/os pertenecientes al programa, cuyos materiales de tesis o TIF se pueden encontrar en la biblioteca de la Facultad." 
Sin embargo, este año el desafío es diseñar una propuesta pedagógica atravesada por la pandemia donde no son posibles las clases presenciales, como sí ocurrió otros años y a partir de la decisión del TCP de habilitar oficialmente a las personas detenidas utilizar teléfonos celulares y otros dispositivos tecnológicos para comunicarse con las familias o estudiar (aunque el Protocolo del SPB prohíbe que puedan acceder a redes sociales), estas definiciones resultan clave en el diseño de la propuesta académica para la continuidad del ciclo lectivo 2020 en el marco del proyecto pedagógico de la Extensión Áulica.

Educación superior en cárceles. ¿Qué acción pedagógica es posible en contexto de pandemia? Estrategias académicas generales de la FPyCS-UNLP

En función de las medidas adoptadas por el Gobierno Nacional y la UNLP que, entre otras, determinan la postergación del inicio del ciclo lectivo 2020, desde la FPyCS, donde las autoras de este artículo participamos como estudiantes, docentes, adscriptas a la docencia, investigadoras y extensionistas, "se brinda a la comunidad educativa, a través de la iniciativa \#PerioEnCasa, una serie de propuestas virtuales para llevar a cabo durante el aislamiento obligatorio" (FPyCS, 2020).

La iniciativa se enmarca en un conjunto de acciones y estrategias político-institucionales que la casa de estudios se propuso implementar ante la emergencia sanitaria y entre las que se cuenta: el dictado de las materias de grado y posgrado por medio de clases virtuales, así como también el desarrollo de mesas de examen y de defensas de TIF a distancia para propiciar la continuidad pedagógica y la terminalidad educativa en el marco de la cuarentena.

La casa de estudios activó inmediatamente mecanismos que permitan garantizar el dictado de las asignaturas del primer cuatrimestre desde la modalidad de educación a distancia (EAD) y, en torno a ello, la implementación de una serie de recursos y de infraestructura tecnológica como la ampliación de la oferta académica por medio de las Aulas Web UNLP y la creación de un multisitio propio que permita alojar las webs de las cátedras.

Se denominan clases virtuales o a distancia a aquellas propuestas académicas que, de la mano de distintos recursos tecnológicos, se proponen desarrollar un proceso de aprendizaje. Por caso, las escuelas primarias y secundarias tienen experiencias de educación virtual como el programa Conectar Igual. Las instituciones de educación superior también vienen desarrollando estrategias de EAD desde hace años. 
En ese sentido Sebastián Benítez Larghi nos recuerda que "esos recursos, que ya estaban disponibles, permitieron que las prácticas de la educación a distancia ahora se desplieguen de manera casi inmediata: hay un enorme reservorio de materiales elaborados concienzudamente para el acompañamiento pedagógico, fruto de una decisión estatal orientada a diseñar plataformas como Educ.Ar o $\mathrm{ABC}$, programas educativos y contenidos propios, nacionales y de carácter público".

La virtualización de las clases en el caso de la FPyCS se vio acompañada por la estrategia denominada "Web de cátedras", que permite alojar contenido de cada asignatura resguardado en los servidores de la Facultad. Así cada materia puede subir materiales como sus programas, guías de trabajos prácticos, bibliografía, textos, imágenes, audios y videos. Toda esa información es posible de navegar de forma ágil y con datos bonificados, tras la iniciativa implementada para que no genere gasto económico a quien navegue en los sitios con extensión ".edu.ar".

Estos recursos estuvieron acompañados de un rico e intenso proceso de capacitación, del cual pudimos participar, por medio de encuentros de asesorías en línea para la educación a distancia, organizados por el Programa de Apoyo a la Educación a Distancia - PAED dependiente de la DGEaDyT de la Secretaría Académica de la UNLP.

\section{Estrategias pedagógicas de la cátedra MMP2}

Nuestra práctica como docentes en la FPyCS se enmarca en la materia Modernidades, Medios y Poder, cátedra 2 (MMP2) vii. Se trata de una asignatura correspondiente al Ciclo Básico de la Tecnicatura en Comunicación Social (título intermedio) y de la Licenciatura en Comunicación Social, en el Plan de Estudios vigente, generalmente la cursan estudiantes ingresantes.

El equipo docente respondió a la sugerencia institucional de diseñar una web de cátedra para la estrategia de EAD, por lo que trasladamos a esta nueva plataforma recursos de nuestras clases que teníamos en línea en un weblog. Asimismo, hubo un acuerdo del equipo de cátedra para que cada docente, tanto de las clases teóricas como de las clases prácticas, desarrolle un aula virtual en la plataforma Classroom.

Estrategias particulares para la Extensión Áulica 
Al mismo tiempo, surgieron una serie de interrogantes, de dudas e incertidumbres acerca de cómo desarrollar el dictado de nuestra asignatura en la Extensión Áulica Unidad 9, en una experiencia donde estudiantes y docentes no podemos encontrarnos de manera presencial. ¿Es posible ofertar el aula virtual de Classroom? ¿Todo el estudiantado contará con tecnología disponible? ¿Tendrán datos para usar en la lectura de nuestros materiales de estudio? ¿Se podrán alcanzar los materiales y actividades por Correo Argentino? ¿Usamos nuestros correos electrónicos? ¿implementamos las clases por Whatsapp?

La pregunta inicial de fondo era (y sigue siendo) ¿Cómo garantizar el acceso igualitario, equitativo y no discriminatorio cuando pensamos la continuidad educativa en la Extensión Áulica Unidad 9? El compromiso de lograr determinados fines se presenta doblemente desafiante si se carece de recursos creativos necesarios para lograrlos. Esto implica pensar en las condiciones agravadas del contexto en que estas personas en situación de prisionización pueden estudiar, en las posibilidades de acceso, en los medios que necesitan para acceder: medios técnicos, softwares, aplicaciones informáticas, y también en las necesarias mediaciones y adaptabilidad de los contenidos, actividades y evaluaciones.

Algunas de estas preguntas han ido encontrando respuestas a medida que lo dialogamos colectivamente al interior de la cátedra, con docentes de las otras cátedras que este primer cuatrimestre del ciclo 2020 participan de la Extensión Áulica, con el equipo de coordinación del Programa "Educa", el Centro de Estudiantes y las distintas Secretarías de la Facultad. También estuvimos y seguimos estando al corriente de cómo la continuidad pedagógica en otros niveles educativos de la modalidad privación de la libertad se está llevando adelante y las dificultades que se presentan.

Nuestra materia tiene como objetivo abordar la relación dialéctica entre sociedad moderna, medios de comunicación e industrias culturales a lo largo de la historia. La asignatura está estructurada en tres grandes ejes de contenidos: modernidad/modernidades; medios, comunicación/poder; globalización/convergencia. La cursada está dirigida principalmente a estudiantes ingresantes, personas que por primera vez tienen acercamiento a la vida universitaria.

En el caso de la matrícula de la Extensión Áulica Unidad 9 presumimos un perfil de estudiantes que cuentan trayectorias educativas disímiles, desiguales, diferentes, pero en todos los casos debilitadas (Zapata y Nieto, 2016), producto de un sistema educativo que en Argentina se ve 
caracterizado principalmente por la fragmentación y la estratificación, en cuanto al acceso; la permanencia; la apropiación de conocimientos, entre otros factores.

A esto se le suman las condiciones de detención, los aspectos que mencionamos más arriba en relación con el hacinamiento, la carencia de recursos básicos para garantizar la seguridad alimentaria y sanitaria; la falta de contacto con familiares y defensores ante el doble aislamiento social que se encuentran padeciendo.

En este contexto, proponemos el abordaje de los contenidos de la asignatura enmarcado en la estrategia académica general que impulsó la FPyCS: la virtualidad de las clases y la disponibilidad de diversos recursos tecnológicos para mediar el proceso de enseñanza y aprendizaje.

La propuesta pedagógica situada

El diseño de la propuesta pedagógica retoma algunas ideas centrales: en principio que el acto de enseñar no existe sin el aprender, el acto de enseñar exige la existencia de quien enseña y de quien aprende. En ese sentido, siguiendo a Paulo Freire, comprendemos que la situación de estudiar siempre implica el leer y que esto no es mero entretenimiento sino leer el mundo, porque enseñar a leer implica comprometerse con la experiencia de la comprensión.viii1

En este marco, la propuesta exige sintetizar los materiales de la instancia teórica y práctica en un mismo recorrido con las limitaciones que las cárceles actuales tienen. Les estudiantes de la extensión áulica no acceden a fotocopias, material bibliográfico ni de archivo. La educación en contexto de encierro es un desafío en sí mismo, no sólo porque es un derecho que la Universidad busca garantizar, sino porque les estudiantes en su situación de restricción de la libertad ambulatoria encuentran cercenados otros derechos, como hemos señalado.

Para el desarrollo de esta propuesta situada pensamos, a priori, desarrollar diez clases consecutivas armonizando en cada una de ellas aspectos prácticos y teóricos. Es decir, que cada clase cuente con una recomendación bibliográfica y una propuesta práctica a los fines de cristalizar, en situaciones del cotidiano, lo que el material detalla y abre pensar. 
La propuesta reconoce que les estudiantes no cuentan con una PC propia donde trabajar, que no tienen acceso a Internet y que, en el mejor de los casos, utilizan los celulares con datos móviles limitados para acceder al material. Por ello, desde la cátedra se decidió publicar el material en la extensión ".edu.ar" porque es de navegación gratuita a partir del compromiso que asumieron el Ente Nacional de Comunicaciones (ENACOM), el MEN y las empresas prestadoras de servicios de telefonía e internet. Con este acuerdo se liberó el uso de datos móviles para que les estudiantes accedan a las plataformas educativas de las universidades nacionales sin preocuparse por el consumo de datos.

La propuesta también contempla el recorrido previo educativo de les estudiantes, por ello se seleccionaron materiales didácticos diversos, capaces de facilitar la lectura y el desarrollo de tareas prácticas sin afectar la calidad de la propuesta en general. Es decir, se plantean lecturas adaptadas, sin que por ello pierdan su rigor académico.

Abandonamos la posibilidad de proponer material audiovisual ya que, en general, dichos materiales se enlazan en sitios externos a los de las universidades nacionales y por ello su visualización consume datos y nuestres estudiantes de la Extensión Áulica no cuentan con suficientes créditos telefónicos de saldo garantizados para tal fin.

Pasadas tres semanas del inicio de clases, aún no tenemos un diagnóstico concluido acerca de cuántas personas inscriptas en nuestra materia cuentan con acceso a dispositivos técnicos y con la adecuada conectividad que le permitan acercarse a nuestra propuesta pedagógica y transitarla adecuadamente. Se van sumando lentamente a la materia y con muchas dificultades, principalmente técnicas.

Esto nos alerta sobre los distintos aspectos que, a priori, se presentan de manera "limitante" y "contradictoria" (GESEC, 2020) a la hora de implementar las TICs en la educación en cárceles: la restricción de uso de aparatos tecnológicos en espacios educativos (sólo se permite el uso en las celdas o pabellones de alojamiento). En la práctica, esto genera una restricción importante toda vez que limita la posibilidad del encuentro. En consecuencia, se presentan las limitaciones materiales que permitan garantizar el acceso y sostenimiento económico de los aparatos; las profundas desigualdades ante el acceso simbólico a los recursos y contenidos por medio de los dispositivos digitales; y las restricciones en los modos de uso.

Otro aspecto para considerar es la importancia de lo vincular y de las relaciones que se construyen en el marco de un proceso pedagógico. Esperamos que la educación 
mediada por TICs no implique perder de vista esta dimensión humana del acto educativo. No caben dudas de que la integración de las tecnologías favorece procesos educativos en la cárcel. Pero esto será así, siempre y cuando haya políticas concretas con una mirada integral que posibiliten la formación de docentes y estudiantes en la integración y uso de las TICs, es decir, a través de políticas educativas pensadas, diseñadas y adecuadas para este contexto. (GESEC, 2020, pág. 4)

Se trata de que como docentes podamos pensar la posibilidad del hecho educativo desde las 4Aes a las que aludimos más arriba, de situar la propuesta en torno de las condiciones de accesibilidad (en este caso ya dispuesta por la política universitaria); de disponibilidad técnica y de conectividad (facilitada de momento por los teléfonos celulares o computadoras que acercan las familias); de la necesaria adaptabilidad de los contenidos, actividades e instancias de evaluación; de la necesidad de generar las condiciones que permitan garantizar que los procesos sean de calidad y, al mismo tiempo, equitativos y pensando en cada estudiante.

En este camino nos encontramos: con entusiasmo creativo para el diseño de la propuesta; con expectativas ante la interacción medida por dispositivos tecnológicos con nuestres estudiantes; con interrogantes abiertos de cara a la continuidad del proceso; con la certeza de trabajar para una Universidad Pública que quiere estar cerca del pueblo (en ciudades lejanas a las capitales, en los barrios, allí donde poco suele llegar y también en las cárceles).

\section{Experiencias concretas en desarrollo, recursos y continuidades}

Como primera estrategia, en nuestra web de cátedra generamos una pestaña específica para publicar contenidos diseñados para las clases en la Extensión Áulica Unidad 9, que este cuatrimestre nuestra materia se dicta por primera vez de manera virtual (y que genera una serie de desafíos y complejidades, que se suman a otros que, de por sí, caracterizan a la educación en los contextos de encierro punitivo).

La decisión acordada en el equipo docente fue publicar las clases, semana a semana, en un archivo pdf., acompañado de otro archivo con la propuesta bibliográfica de apoyo. La idea es que tengan unificados los recursos para que les estudiantes descarguen el material y no tengan que navegarlo en línea.

Las clases apelan a propuestas pedagógicas donde deben realizar síntesis del material, líneas de tiempo, mapas conceptuales o resúmenes que destaquen las ideas principales de las 
lecturas. Por las condiciones estructurales reinantes no pueden desarrollar otro tipo de propuestas.

En segundo término, definimos generar las primeras interacciones mediante el correo electrónico institucional de la cátedra, que dejamos publicado en la pestaña respectiva de la web y una indicación para relevar la situación y realizar un diagnóstico general y de cada estudiante que se comunique con el equipo de cátedra:

- a) tu nombre y apellido,

- b) en qué Plan de Estudios estás cursando (1998 o 2017)

- c) en qué unidad te encuentras

- d) con qué recursos tecnológicos disponibles cuentas (teléfono, computadora, tablet u otro)

- e) qué tipo de conectividad tienes (datos, wifi de la institución).

Sus trabajos prácticos son remitidos al equipo docente a través del mismo correo electrónico institucional de la cátedra. Es el e-mail la modalidad definida para el contacto y la interacción. La primera semana se contactaron 8/23; en la segunda semana el nivel de la comunicación decayó y ya en la tercera semana de clases (que estamos atravesando mientras cerramos este artículo) llegaron los primeros trabajos prácticos: en algunos casos se evidencia que produjeron en hoja de papel, sacaron fotos de la producción y enviaron por correo; en otros casos enviaron sus trabajos en documento de word.

Nuestres estudiantes están alojados, principalmente, en las unidades penitenciarias 1 (Olmos); 9 (La Plata) y 33 de mujeres Los Hornos. También tenemos en la cursada virtual a una estudiante que fue recientemente liberada, que podría haber retomado las cursadas de la sede Bosque, pero que prefirió la continuidad en la sede Extensión Áulica U9 para sentirse contenida desde ese lugar de la institucionalidad de la Facultad.

Otros equipos de cátedra se encuentran implementando estrategias situadas para las materias que se dictan en Extensión Áulica mediante el recurso de las webs de cátedras, grupos en la red social Facebook y correo electrónico institucional del equipo docente.

En este sentido, consideramos que la continuidad educativa en esta sede territorial en medio de la pandemia resulta una experiencia que nos desafía en el rol docente y que, al mismo tiempo, nos plantea otras preguntas: ¿cómo diseñar estrategias pedagógicas creativas que 
contengan a les estudiantes privados de su libertad? ¿Qué hacer ante los nuevos desafíos estructurales que una enfermedad le genera al sistema educativo nacional? ¿De qué manera podremos educar más y mejor en contexto de encierro? ¿cómo abordar la presentación de la crisis carcelaria en la agenda pública?

Interpelar los relatos mediáticos

En el medio de la emergencia sanitaria, en la agenda mediática local se instaló una fuerte discusión con tono de generar polémica, sobre la situación que se vive en las cárceles y, particularmente, sobre la decisión tomada por el TCP y las recomendaciones de la Cámara Federal de Casación respecto de impartir morigeraciones.

Aparecieron noticias donde se habla de "un plan para liberar presos", de conmutar o indultar penas sobre delitos graves, de la cantidad de "violadores", "narcos" y "femicidas" que estarán "sueltos" y una serie de apreciaciones disparatadas que, no sólo no se vinculan con las cifras y situaciones de personas a quienes se les otorgó prisión domiciliaria, sino que se saca de contexto jurídico cada caso particular para ponerlo en un genérico espectáculo mediático.

La emergencia general y el deficiente abordaje del tema tiene como resultado, al menos, siete personas muertas por motines realizados en Santa Fe y Florencio Varela, algún que otro liberado que fue nuevamente detenido y un sin fin de cuestionamientos de parte de sectores a quienes los medios de comunicación hegemónicos le otorgan voz.

El debate se instala en torno de los derechos de las personas presas, pero por supuesto que no se hace desde una perspectiva de derechos. Las personas privadas de su libertad ambulatoria por disposición judicial ¿tienen derechos? ¿cuáles? ¿colisionan entre sí? ¿es la salud o la seguridad la que está en juego? La discusión de estos temas ocupa gran parte de la agenda pública al momento de redactar este artículo.

Por esta razón, y como somos docentes de una asignatura que busca interpelar el discurso mediático, hacemos un llamado de alerta y de repudio sobre aquellos discursos mediáticos, que se profundizaron por estos días, con posicionamientos de desprecio hacia el otro. Desde este rol repudiable, periodistas y editorialistas alientan el odio con sus modos de relatar una realidad centrada no en información sino en opiniones discriminatorias y estigmatizantes.

Esos discursos mediáticos, que resultan adversos a toda perspectiva basada en los derechos humanos y la inclusión social, no hacen otra cosa que alejar a aquellas personas que se 
encuentran en situaciones de extrema vulnerabilidad de la resolución de sus situaciones y del acceso y al ejercicio de los derechos que les corresponden por ley.

¿Comunicación irresponsable o comunicación del castigo?

Resulta inminente debatir el abordaje comunicacional respecto de esta emergencia sanitaria, puesto que, en este contexto, muchas de las personas que cumplen con el aislamiento social preventivo y obligatorio tienen como única fuente de información el relato de los medios hegemónicos. Si bien existen otros espacios de comunicación -característica de esta época ante las estrategias de difusión y circulación en el espectro de las redes sociales-, la hegemonía de la palabra continúa concentrada en unas pocas empresas.

¿Qué quieren decirnos las empresas mediáticas respecto de la situación carcelaria? En general el discurso que resuena es que, al permitir las salidas de muchas de las personas que están en condiciones de hacinamiento, de falta de acceso a la salud y a la educación es un "error moral" y que deben permanecer en esos lugares del horrror, cuesten las vidas que cuesten.

El pronunciamiento de las propias personas en situación de cárcel, de las familias, de las organizaciones de DDHH y de otres actores, es que la situación de emergencia en las cárceles es producto de decisiones políticas. También el reconocimiento de que las falencias del sistema penal son estructurales y, en esta emergencia, significan un riesgo inminente de vida.

En los discursos mediáticos pocas veces se destaca que cuando se habla de prisiones domiciliarias, por ejemplo, no se refiere a cualquier persona que esté en situación de encierro, sino a aquellas que no lo estén por delitos violentos.

Esos discursos están producidos desde lógicas punitivas que resuenan en el sentido común, rodean al debate que se instala en la agenda mediática y resignifican otros sentidos comunes. Hemos sido testigo de comentarios en boca de periodistas semejantes a: "por mí, paredón y balas", en referencia a los reclamos llevados adelante en unidades penitenciarias de todo el país. Y en parte el dicho se cumplió porque en la Unidad 23 de Florencio Varela a un joven lo mataron con balas de plomo.

Desde la perspectiva de los feminismos populares y de diversos espacios críticos del sistema penal se plantea la necesidad de debatir el rol del Estado respecto de la respuesta ante la comisión de delitos, de la toma de posición ante perspectivas tan amplias y complejas como las 
denominadas punitivistas, antipunitivistas, garantistas, etc. Organizaciones sociales (como Otrans, por ejemplo) que trabajan acompañando a personas en situación de vulnerabilidad y que visibilizan situaciones de abuso, violaciones, femicidios, transfemicidios, travesticidios, también trabajan en espacios de encierro y buscan visibilizar el colapso estructural del sistema penitenciario

$\mathrm{Si}$ atendemos a las cifras que marcan el aumento, especialmente de los femicidios y de los múltiples tipos de violencias de género durante el ASPO, queda claro que la respuesta judicial a la comisión de este tipo delitos no puede ser, en este contexto, "antipunitivista" ni "anticarcelaria". ¿Pero es posible pensar medidas alternativas al encierro punitivo sin que estén en riesgo las víctimas de este tipo de delitos?

Se corre riesgo de vida si a un varón violento (que amenazó a una mujer, que violó una medida perimetral, o que cometió abuso contra la integridad sexual) se le otorga el beneficio con una medida de prisión domiciliaria por constituir población de riesgo (enfermedad infectocontagiosa o respiratoria grave, mayor de 65 años, etc.). No tenemos dudas sobre esto. Porque fuera de la cárcel, aún no existen dispositivos desarrollados en todas las escalas territoriales para trabajar con esa persona violenta. Por eso la resolución del TCP pone el acento en que cada juzgado o tribunal determine los casos particulares sin poner en riesgo a las víctimas.

En ese sentido, también nos genera interrogantes si el discurso mediático que narra los reclamos por elementos de higiene en las unidades penitenciarias como "motines" y que despliega frases estigmatizantes lo hacen pensando en las mujeres y en aquellas identidades disidentes que podrían estar en riesgo. ¿O simplemente se instalan desde la punición y el castigo por sí mismo?

Así como los casos de "gatillo fácil" despiertan reacciones, por lo menos polémicas, la potencial liberación de personas presas que conforman la población de riesgo ante un eventual contagio, despierta el lado más violento de la sociedad: el sentimiento de odio; la necesidad de castigo y el deseo de dar muerte.

Los medios reproducen ese discurso criminalizante, apuntan a una porción de la sociedad para condenarla a la muerte, para negarle sus derechos (el derecho a la salud, el derecho a huelga). ¿Por qué? Porque se trata de vidas que no valen la pena. Hay vidas que merecen la pena (incluso se habla "del niño por nacer") y hay otras que ni siquiera merecen ser consideradas vidas. 
Tal como lo describe Judith Butler (2010) en su libro Marcos de guerra, las vidas lloradas: en el sistema económico y político que conocemos existen vidas que merecen vivir y otras que ni siquiera pueden ser catalogadas como tales. En una sociedad en la que la propiedad privada vale más que la vida, aquella persona que atenta contra la propiedad privada, lo único que merece es la muerte.

Las estadísticas del Ministerio de Justicia y Derechos Humanos de la Nación (2018), dan cuenta que de un total de personas detenidas en todo el país el $44,55 \%$ tiene una causa penal por robo o tentativa de robo; el 13,56 \% por Infracción a la Ley 23.737 (tenencia o venta de estupefacientes); en tanto que el 13,86 está por otros delitos contra las personas/propiedades/seguridad pública y el 11,32 por delitos contra la integridad sexual.

Resulta significativo que de las personas -algunas de ellas con cargo de diputada nacional- y sectores que alentaron las campañas públicas para que no se liberen a las personas presas, o que refirieron a hipotéticas e inverosímiles "patrullas de liberados para amenazar a jueces y para expropiar el capital", ninguna de ellas planteó la posibilidad de fomentar espacios alternativos transitorios, que al menos, posibilitaran una reducción del nivel de hacinamiento que nadie puede negar.

En cambio, esos discursos, producidos, difundidos y replicados como retumbos de cañones en diversos medios de comunicación, generan un efecto de condena eterna a la insalubridad hasta la muerte de quienes están en situación de cárcel hoy. Una institución que sí se pronunció al respecto presentando una alternativa fue la iglesia católica, cuya voz compasiva apareció en una nota del diario La Nación, y enfatizó que los "presos no pierden la dignidad" y ofreció hospedaje para eventuales liberaciones.

No esperamos que la iglesia que hable de derechos. Pero sí a agentes de lo público, referentes políticos, periodistas y comunicadores a quienes parece costarle madurar la vida democrática y la garantía de derechos para todes. Y esta idea de no pensar en clave de derecho encubre una fuerte matriz punitivista. Así es que desde los vecindarios aparecen personas que denuncian (y muchas veces entre sí) acciones por incumplimiento del ASPO y se genera una "guerra" de castigo en pasillos, ascensores y en la calle:

- Yo te denuncio primero por pasear al perro.

- ¡No! Yo, porque entró a tu casa alguien que no es del edificio.

- Andate a vivir a otro lado, vos que sos enfermera nos vas a contagiar a todos. 
Este tipo de reacciones evidencian (porque según el criterio de muchos y muchas las cárceles estarían por fuera) las lógicas punitivas que se imponen en lo cotidiano. Basta con recordar los episodios de linchamientos sistemáticos en plena vía pública. Y cuánta responsabilidad tienen los medios de comunicación para mostrar y relatar aquello y la tienen ahora para opinar a quién debe llegarle primero el Estado.

Se enfatiza que el Estado tiene que llegar a "todos": y ahí están las historias de quienes el aislamiento los encontró varados en otros países. Pero en ese "todos" ¿también están quienes se encuentran en los barrios con dificultades para llevar un plato de comida a su mesa? La amenaza del virus no discrimina clases sociales.

Las vidas solo son vidas si hay alguien, si existe "un Otro", que las designa como tales. Hay vidas que sólo son valoradas de forma ficcional, desde la espectacularización. Y hay otras vidas que no merecen la pena. Las vidas de las personas presas a las que el Estado no puede garantizarle condiciones mínimas de detención son esas vidas.

¿Cuántas de las personas que hoy (jueves 30 de abril mientras entregamos este artículo) cacerolean para que "no liberen presos", han colaborado para aumentar el rating de series como El Marginal, e incluso se emocionaron con la apuesta estética y dramática de Underground? También seguramente hubo muchas otras que se sorprendieron, y aclamaron a los gritos frases como "¡Dale, matalo!". Seguramente fue más de una. Lo dicen los índices de medición de audiencia y la llegada a Netflix de la producción. Esto habla de la espectacularización de la vida y de la muerte, de la banalización de las violencias.

¿Qué hacer ante esto? Desde nuestra materia trabajamos para desnaturalizar el discurso de los medios; para que nuestres estudiantes puedan reconocer ciertas lógicas puestas en juego en los modos de producción, circulación y apropiación de las noticias; de identificar ciertas estéticas narrativas dispuestas al momento de contar "lo real"; de ubicar los discursos en el espacio material y simbólico de la estructura económica; de reconocer las políticas de comunicación; de advertir y desalentar infodemia.

También buscamos proponer y fomentar otros modos de producir; de consumir y de hacer circular la información; el reconocimiento otros modelos de comunicación mediática (populares, educativas, organizacionales, comunitarias, estatales, universitarias, sindicales) capaces de romper el cerco informativo hegemónico o, al menos, empezar a desarmar aquellas 
construcciones discursivas impregnadas de violencia y de odio para reemplazarlas por otras fundadas en la colectividad.

Quizás no sea este el mejor momento para plantearnos estos debates. ¿Hay un mejor momento para plantearse ciertos debates? Seguro quedará pendiente para otras incidencias e invitaciones que vendrán. De lo único que no dudamos es de que la comunicación y la educación, su ejercicio y su llegada son derechos inalienables para todas, todos y todes.

Bibliografía

AAVV (2020) Web de Cátedra "Modernidades, Medios y Poder" de la FPyCS-UNLP https://perio.unlp.edu.ar/catedras/modernidadescat2/extension-u9/, consultado en abril de 2020.

Butler, J. (2010). Marcos de guerra: las vidas lloradas (Vol. 168). Grupo Planeta (GBS).

CONICET (2020) "Relevamiento del impacto social de las medidas del aislamiento dispuestas por el PEN", disponible en https://www.conicet.gov.ar/,consultado en abril de 2020.

GESEC (2020) "Abogamos por la garantía y el disfrute del derecho a la educación pública en cárceles en el contexto de la pandemia", La Plata. http://www.gesec.com.ar/abogamos/, consultado en abril de 2020.

Instituto Internacional de la UNESCO para la Educación Superior en América Latina y el Caribe (2008) "La Universidad es Conferencia: Conferencia Regional de Educación Superior", Cartagena de Indias.

Educación en tiempos de pandemia - consejos de especialistas para enriquecer las aulas virtuales

Kemelmajer, C. (2020) "Educación en tiempos de pandemia - consejos de especialistas para enriquecer las aulas virtuales", en https://conicet.blogspot.com/, consultado en abril de 2020.

Muñoz, V. (2004). El derecho a la educación. Informe del Relator Especial sobre el derecho a la educación. Comisión de Derechos Humanos, Naciones Unidas.

Nikken, P. (1994) "El concepto de derechos humanos" en IIDH (ed.), Estudios Básicos de Derechos Humanos, San José.

PAUC (Programa de Acompañamiento Universitario en Cárceles) https://unlp.edu.ar/pauc, consultado en abril de 2020. 
Rodríguez Alzueta, E. (2020). "Pandemonium", en Revista El Cohete a la luna. https://www.elcohetealaluna.com/pandemonio/,consultado en abril de 2020.

Ministerio de Justicia y DDHH de la Nación (2019) Informe Anual República Argentina SNEEP 2018, https://datos.gob.ar/, consultado en abril de 2020.

Scarfó, F. y Zapata, N. (2013) "Obstáculos en la realización del derecho a la educación en cárceles. Una aproximación sobre la realidad argentina" Cátedra UNESCO de investigación aplicada para la educación en la cárcel, Montreal.

Notas

i- El historial de visitas en el artículo "cuarentena" de Wikipedia, en el periodo 29/02/2020 - 29/04/2020, registra un total de 1.488 .370 consultas y ha tenido cientos de ediciones en estos días (un 50 por ciento de ediciones en el último periodo desde que se creó el artículo en 2004)

ii- Desde el año 1995 la FPyCS-UNLP desarrolla experiencias de Extensión Áulicas en distintos territorios del país. Se trata de una política de inclusión social que promueve la educación superior en comunidades que profundizan sus opciones educativas como estrategia de desarrollo local. El concepto Extensión Áulica consiste en una modalidad de articulación entre la Universidad y la comunidad. La propuesta consiste en el dictado completo en cada territorio de las distintas opciones de formación en comunicación que posee la Facultad con los mismos contenidos y equipos docentes que componen la sede de la ciudad de La Plata.

iii- Se trata de cinco personas muertas en las cárceles del penal de la provincia de Santa Fe y del caso de Fernando Rey, que se encontraba detenido en la Unidad Penitenciaria № 23 de Florencio Varela (Buenos Aires) y, que, tras diversas versiones sobre su muerte, la justicia comprobó que recibió varios impactos de bala de plomo en su cuerpo. 
iv - La SCJBA dictó, además, la resolución 54-20 por medio de la que dispone un correo electrónico único para recibir exclusivamente los pedidos vinculados al estado de salud de las personas privadas de libertad.

v - El "Protocolo para el uso de teléfonos celulares por parte de personas privadas de la libertad en el ámbito del Servicio Penitenciario Bonaerense", se instrumentó en la provincia de Buenos Aires el 1 de abril de 2020 y su puesta en marcha generó sendos debates en tono de polémica en los noticieros y redes sociales, con el argumento de que "ahora podrán hacer secuestros virtuales desde las cárceles".

vi. La Mesa está integrada por unidades académicas de la UNLP, UBA, UNC, UNR, UADER, UNSAM, UNS, UNCA, UNER y UNICEN. A este pronunciamiento adhirió, además, la organización social académica GESEC (Grupo de Estudios sobre Educación en Cárceles).

vii 7- En el anterior Plan de Estudios 1998 la asignatura se denomina “Comunicación y Medios”.

viiiSegún le expresó al diario La Nación el obispo Juan Carlos Ares, titular de la Pastoral Carcelaria del Episcopado, la Iglesia Católica se ofreció a participar de un espacio de diálogo para resolver la crisis planteada en las cárceles y la polémica que generó la liberación de detenidos/as bajo ciertas condiciones, que aún lejos está de ser masiva o sistemática. "Por más que esté preso, una persona no pierde la dignidad", aclaró el monseñor, cosa que parece una verdad sumamente conocida, pero se aleja de los argumentos de los sectores políticos, judiciales y mediáticos carentes de perspectiva de derecho. 